\title{
Preparation and Characterization of an Amphipathic Magnetic Nanosphere
}

\author{
Yongsheng Ji, ${ }^{1}$ Ruihong Lv, ${ }^{1}$ Zhigang Xu, ${ }^{2}$ Chuande Zhao, ${ }^{2}$ and Haixia Zhang ${ }^{2}$ \\ ${ }^{1}$ College of Pharmacy, Henan University of Traditional Chinese Medicine, Zhengzhou 450000, China \\ ${ }^{2}$ Key Laboratory of Nonferrous Metal Chemistry and Resources Utilization of Gansu Province, Lanzhou University, \\ Lanzhou 730000, China
}

Correspondence should be addressed to Haixia Zhang; zhanghx@lzu.edu.cn

Received 24 November 2013; Accepted 4 January 2014; Published 5 March 2014

Academic Editor: Xiu-Ping Yan

Copyright (C) 2014 Yongsheng Ji et al. This is an open access article distributed under the Creative Commons Attribution License, which permits unrestricted use, distribution, and reproduction in any medium, provided the original work is properly cited.

\begin{abstract}
The amphipathic magnetic nanospheres were synthesized using $\mathrm{C}_{8}$ and polyethylene glycol as ligands. Their morphology, structure, and composition were characterized by transmission electron microscope, Fourier transform infrared, and elementary analysis. The prepared materials presented uniform sphere with size distribution about $200 \mathrm{~nm}$. The magnetic characteristics of magnetic nanomaterials were measured by vibrating sample magnetometer. The target products had a saturation magnetization value of $50 \mathrm{emu} \mathrm{g}^{-1}$ and superparamagnetism. The adsorption capability was also studied by static tests, and the material was applied to enrich benzenesulfonamide from calf serum. The results exhibited that the $\mathrm{C}_{8}$-PEG phase owned better adsorption capability, biocompatible property, and dispersivity in aqueous samples.
\end{abstract}

\section{Introduction}

Magnetic nanoparticles (MNPs) have been the hot topic of scientific research. The reports not only were concerned with their fundamental properties, but also involved the promotion of their characteristics and real applications [1]. The researches concerning the promotion of MNPs' properties focused on the chemical modification onto the surface of MNPs in order to accommodate different aim of application. MNPs have been applied extensively in various fields, for example, magnetic storage media, bioseparation [2-7], drug delivery [8], biomolecular sensors [9], magnetic resonance imaging [10], jet printing [11], and so on.

Recently, magnetic nanoparticles coupled to magnetic carrier technology (MCT) have also been used in solid-phase extraction (SPE), especially for analyzing environmental and biological samples. Song et al. [12], Zhao et al. [13, 14], and $\mathrm{Li}$ et al. [15] utilized bare $\mathrm{Fe}_{3} \mathrm{O}_{4}$ or silicon-coated $\mathrm{Fe}_{3} \mathrm{O}_{4}$ as extracting sorbent to enrich organic pollutants. Yantasee et al. [16] took thiol-modified MNPs to remove metallic ion from water. Qi et al. [17] immobilized $\mathrm{Zr}^{4+}$ ions on the surface of MNPs for selective enrichment of the phosphopeptides. Liu et al. [18] and Yao et al. [19] prepared magnetic $C_{18}$ and $\mathrm{C}_{8}$ microspheres to extract polycyclic aromatic hydrocarbons (PAHs) from water and polypeptide from serum, respectively. Zhang et al. [20] reported the application of magnetic molecularly imprinted polymers (MIP) in solid or semisolid samples for trace analysis of triazines and tetracycline antibiotics. Niu et al. [21] prepared carbonencapsulated MNPs for isolation of organic pollutants. The magnetic MIP with bisphenol A (BPA) as a template was also prepared and applied to extract BPA from environmental water and milk samples [22]. The extraction can be easily achieved by dispersing the magnetic sorbents to sample solution, and the sorbents can be effortlessly isolated from the mixture by an external magnet. Compared to common SPE with nanomaterials, the magnetic SPE not only can build a controllable rebinding process and allow magnetic separation to replace the centrifugation and filtration step in a convenient and economical way, but can also avoid troubles of packing SPE column and the time-consuming process of loading large volume samples. It has been successfully employed in rapid pretreatment of large volume samples.

The dispersivity and compatibility of sorbents used in magnetic SPE are the key factors for their application. Several attempts have been done to fabricate better magnetic 

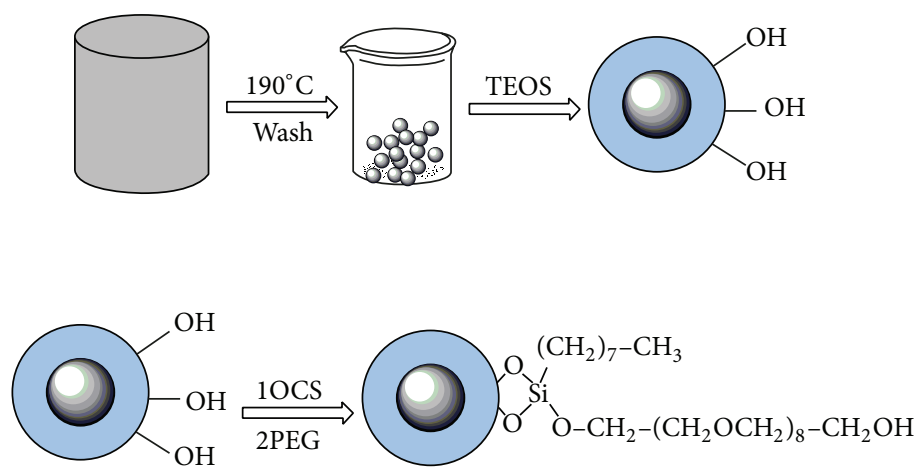

FIGURE 1: Preparation protocol of the magnetic nanospheres.

sorbents. MNPs using $\beta$-cyclodextrin $(\beta-C D)$ as ligand were manufactured, and they showed superior dispersivity in water [23]. Hu et al. [24] improved the biocompatibility of magnetic MIP by combining SPE with liquid-liquid extraction (LLE). Li et al. [25] synthesized amphoteric magnetic microspheres owning hydrophilicity and hydrophobicity. But they could not take consideration to dispersivity and biocompatibility. However, the biocompatibility was necessary for the samples containing biomolecules. $\mathrm{C}_{8}$ and $\mathrm{C}_{18}$ materials are the classical sorbents of SPE. Polyethylene glycol (PEG) due to hydrophilic and biocompatible properties has been used as ligand to prepare various functional materials $[1,26]$. It would be a promising sorbent to simultaneously bond $\mathrm{C}_{8}$ and PEG onto the surface of MNPs.

In the present work, magnetic nanospheres possessing hydrophilic, hydrophobic, and biocompatible properties were produced with $\mathrm{C}_{8}$ and $\mathrm{PEG}$ as ligands. The obtained products were applied to enrich benzenesulfonamide from calf serum.

\section{Experimental}

2.1. Chemicals and Materials. Sodium acetate (NaAc), triethylamine (TEA), polyethylene glycol (PEG), ethylene glycol, and ferric chloride $\left(\mathrm{FeCl}_{3} \cdot 6 \mathrm{H}_{2} \mathrm{O}\right)$ were obtained from Tianjin Chemicals Corporation (Tianjin, China). Tetraethoxysilane (TEOS) and octyltrimethoxysilane (OCS) were purchased from Fluka (Switzerland). These chemicals were all of analytical grade. Sulfamerazine (SMR) was purchased from Alfa Aesar (Karlsruhe, Germany; >98.5\%). Acetonitrile and methanol of chromatography grade were purchased from Dima Technology (Richmond Hill, USA). All other reagents were of analytical reagent grade and the purified water by Milli-Q system was used throughout the experiments.

2.2. Preparation of Magnetic Nanoparticles. The preparation protocol of magnetic nanospheres is shown in Figure 1.

Ferric chloride $(2.7 \mathrm{~g}, 10 \mathrm{mmol})$ was dissolved in ethylene glycol $(80 \mathrm{~mL})$ to form a clear solution, followed by the addition of $\mathrm{NaAc}$ (7.2 g) and polyethylene glycol (MW800, $1.0 \mathrm{~g}$ ). After ultrasonication for $10 \mathrm{~min}$, the mixture was stirred vigorously for $30 \mathrm{~min}$. Then, it was sealed in a teflon-lined stainless-steel autoclave $(100 \mathrm{~mL}$ capacity). The autoclave was maintained at $190^{\circ} \mathrm{C}$ for $10 \mathrm{~h}$ and then cooled to room temperature. The black products $\left(\mathrm{Fe}_{3} \mathrm{O}_{4}\right)$ were washed several times with ethanol and dried at $60^{\circ} \mathrm{C}$ for $12 \mathrm{~h}$.

The obtained magnetic nanoparticles were encapsulated into silica beds as follows [26]: $1.0 \mathrm{~g} \mathrm{Fe}_{3} \mathrm{O}_{4}$ was suspended in $200 \mathrm{~mL}$ ethanol, then ammonia $(25 \%, 30 \mathrm{~mL})$, water $(30 \mathrm{~mL})$, and TEOS $(3 \mathrm{~mL})$ were added sequentially into the generated solution. After degassed, the mixture was stirred vigorously for $2 \mathrm{~h}$ at $50^{\circ} \mathrm{C}$ under nitrogen gas protection. The magnetic particles were separated from the resulting solution by a magnet and the supernatant was discarded. The target materials were rinsed with ethanol to remove excess reactants, neutralized with $\mathrm{HCl}\left(0.1 \mathrm{~mol} \mathrm{~L}^{-1}\right)$, and washed with water. The obtained materials $\left(\mathrm{Fe}_{3} \mathrm{O}_{4} @ \mathrm{SiO}_{2}\right)$ were dried under vacuum at $80^{\circ} \mathrm{C}$ for $12 \mathrm{~h}$.

One gram of $\mathrm{Fe}_{3} \mathrm{O}_{4} @ \mathrm{SiO}_{2}, 60 \mathrm{~mL}$ of toluene, $1 \mathrm{~mL}$ of OCS, and $0.5 \mathrm{~mL}$ of TEA were added successively to a flask. The mixture was refluxed under nitrogen gas protection and stirring for $10 \mathrm{~h}$. After cooling, the magnetic particles were separated from the mixture by a magnet and the $\mathrm{C}_{8}$ bonded phase was rinsed with toluene. The obtained products were dispersed again to $60 \mathrm{~mL}$ of toluene. $1 \mathrm{~mL}$ of PEG (MW400) and $0.5 \mathrm{~mL}$ of TEA were added successively to the mixture. After refluxing and stirring for $10 \mathrm{~h}$, the $\mathrm{C}_{8}$-PEG bonded materials were obtained and rinsed with toluene and ethanol. The products were dried under vacuum at $80^{\circ} \mathrm{C}$ for $12 \mathrm{~h}$.

2.3. Characterization. The obtained products were characterized with JEM1200EX transmission electron microscope (TEM) (Tokyo, Japan) and Nicolet Nexus 670 Fourier transform infrared (FTIR) (MN, USA) spectrometer. Elementary analysis (EA) was performed on a Vario-EL analyzer (Elementar, Germany). Magnetic properties were measured using a vibrating sample magnetometer (VSM) (Lakeshore 7304, USA).

2.4. Adsorption Tests. To measure adsorption capacity, $20 \mathrm{mg}$ of $\mathrm{C}_{8}$-PEG was added into $10 \mathrm{~mL}$ SMR solution with desired concentration. The mixture was shaken for $12 \mathrm{~h}$ at room temperature to facilitate adsorption of SMR onto $\mathrm{C}_{8}$-PEG phase. After the magnetic sorbents were isolated by an external magnetic field, SMR of the supernate was determined by high performance liquid chromatography (HPLC). The chromatographic system consisted of Varian 210 high performance liquid chromatographic pump (CA, USA), $325 \mathrm{UV}-\mathrm{Vis}$ 


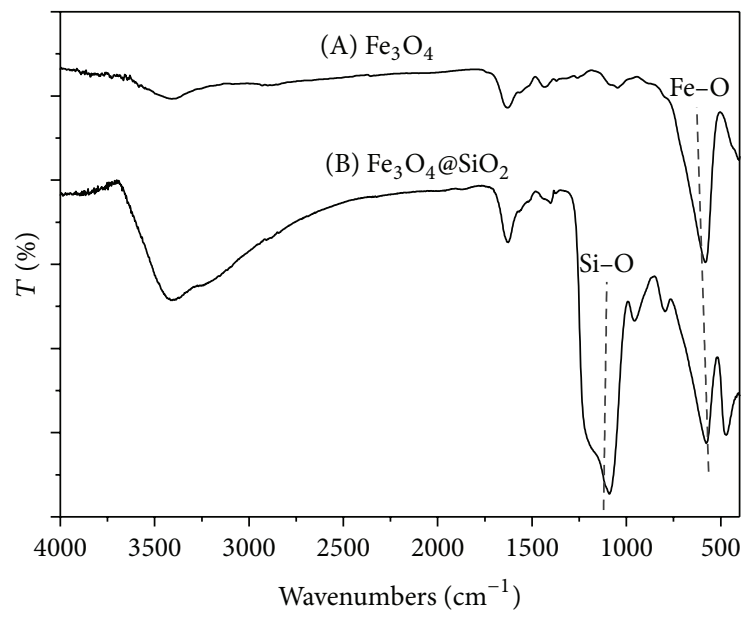

(a)

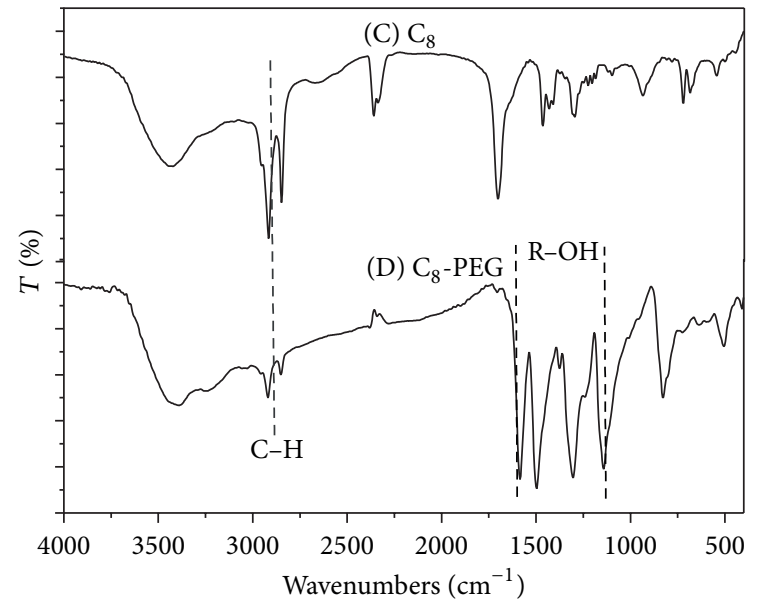

(b)

Figure 2: FTIR of (A) $\mathrm{Fe}_{3} \mathrm{O}_{4}$, (B) $\mathrm{Fe}_{3} \mathrm{O}_{4} @ \mathrm{SiO}_{2}$, (C) $\mathrm{C}_{8}$, and (D) $\mathrm{C}_{8}$-PEG.
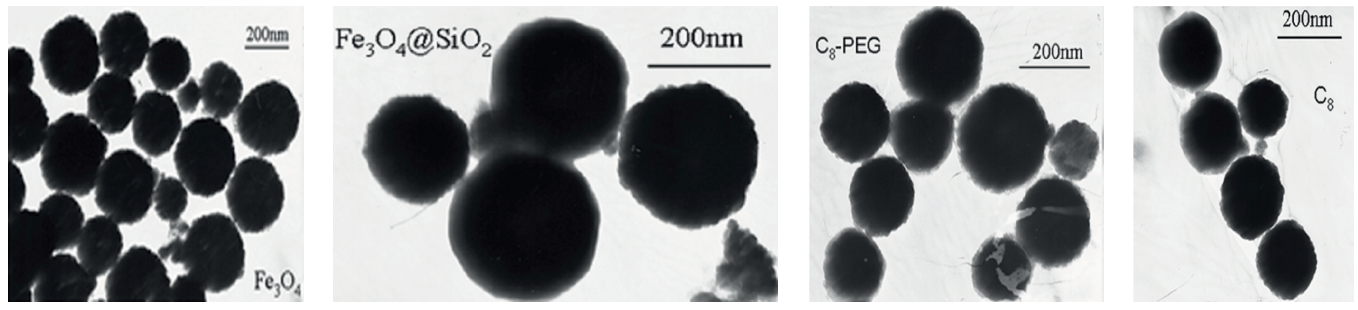

Figure 3: TEM of $\mathrm{Fe}_{3} \mathrm{O}_{4}, \mathrm{Fe}_{3} \mathrm{O}_{4} @ \mathrm{SiO}_{2}, \mathrm{C}_{8}$, and $\mathrm{C}_{8}$-PEG.

detector, and Varian Star Chromatographic workstation. An analytical reversed-phase $\mathrm{C}_{18}$ column $(5 \mu \mathrm{m}, 4.5 \times 250 \mathrm{~mm}$, Dima Technology Richmond Hill, USA) was used. The mobile phase was a mixture of acetonitrile and water $(60: 40$, $v / v$ ) with flow rate of $0.8 \mathrm{~mL} \mathrm{~min}^{-1}$ and the detection was carried out at $263 \mathrm{~nm}$. The same procedure was performed for the $\mathrm{C}_{8}$ bonded material. All tests were conducted in triplicate.

2.5. Application in Real Samples. The samples of calf serum with $10 \mu \mathrm{g} \mathrm{mL}^{-1} \mathrm{SMR}$ were diluted to 4,2 , and $1 \mu \mathrm{g} \mathrm{mL}^{-1}$, respectively. $20 \mathrm{mg}$ of $\mathrm{C}_{8}$-PEG activated by methanol and water was added to $10 \mathrm{~mL}$ of diluted samples, after vortex and standing for $5 \mathrm{~min}$, and then the sorbents were isolated by an external magnet. The sorbents were washed by water and hexane and then eluted by $3 \mathrm{~mL}$ of acetonitrile containing $1 \%$ acetic acid. At last, the elution was analyzed by HPLC-UV.

\section{Results and Discussion}

\subsection{Characterization}

3.1.1. FTIR. All products were measured by FTIR spectrometry step by step, and the results are listed in Figure 2. IR spectra provided clear evidence for the surface modification. Figure 2(a) displays the IR spectrum of the bare magnetic particles and the characteristic band of $\mathrm{Fe}_{3} \mathrm{O}_{4}$ appeared at about $580 \mathrm{~cm}^{-1}$. The unique $\mathrm{Si}-\mathrm{O}$ absorption band was observed from 1000 to $1100 \mathrm{~cm}^{-1}$ (Figure 2(b)), indicating
TABLE 1: Elemental analysis of $\mathrm{C}_{8}$ and $\mathrm{C}_{8}$-PEG phase.

\begin{tabular}{lcc}
\hline Solid phase & $\mathrm{C}(\%)$ & $\mathrm{H}(\%)$ \\
\hline $\mathrm{C}_{8}$ & 2.523 & 0.882 \\
$\mathrm{C}_{8}$-PEG & 2.990 & 1.182 \\
\hline
\end{tabular}

that silica coating was successful on the magnetite surface. In spectra of $\mathrm{C}_{8}$ and $\mathrm{C}_{8}$-PEG bonded particles a typical band of $\mathrm{C}-\mathrm{H}$ stretch was about $2900 \mathrm{~cm}^{-1}$, and the adsorption bands between 1100 and $1600 \mathrm{~cm}^{-1}$ were related closely to R$\mathrm{OH}$, suggesting that the $\mathrm{C}_{8}$ and $\mathrm{C}_{8}$-PEG phase were prepared successfully.

3.1.2. EA. Elemental analysis was employed to measure the composition of $\mathrm{C}_{8}$ and $\mathrm{C}_{8}$-PEG phase products, and the results are listed in Table 1 . Comparing $\mathrm{C}_{8}-\mathrm{PEG}$ to $\mathrm{C}_{8}$ phase, the mass fraction of $\mathrm{C}$ and $\mathrm{H}$ increased, confirming that PEG was successfully bonded onto the surface of magnetic nanospheres. However, it cannot ensure precisely the component of $\mathrm{C}$ and $\mathrm{H}$ on the surface of magnetic nanospheres based on the data of elemental analysis.

3.1.3. TEM. Their morphological feature of all products was observed by TEM in Figure 3. As can be seen, most of the obtained $\mathrm{Fe}_{3} \mathrm{O}_{4}$ nanospheres exhibited regularly spherical shape with size distribution about $200 \mathrm{~nm}$. After the 


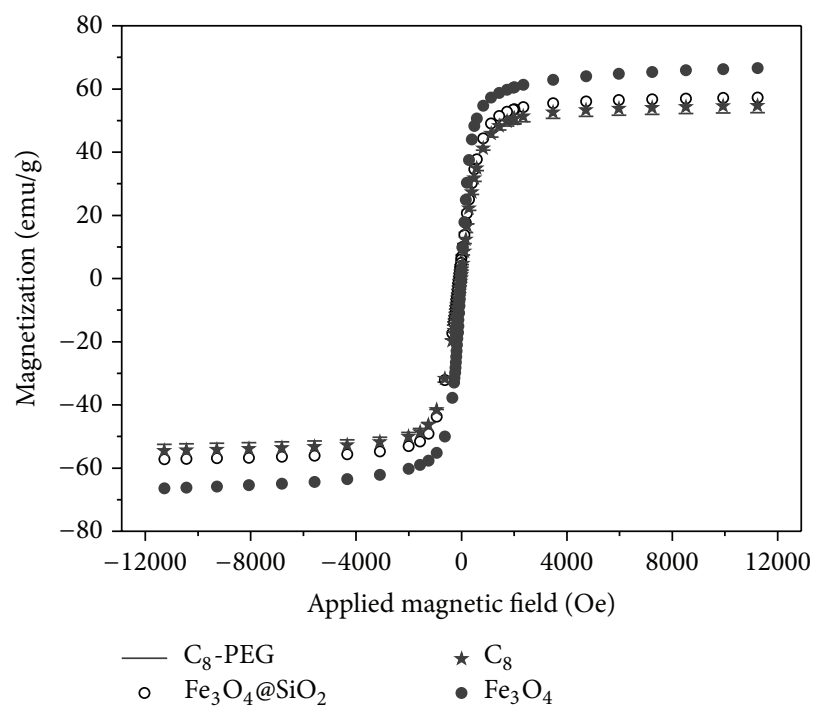

FIGURE 4: VSM magnetization curves of $\mathrm{Fe}_{3} \mathrm{O}_{4}, \mathrm{Fe}_{3} \mathrm{O}_{4} @ \mathrm{SiO}_{2}, \mathrm{C}_{8}$, and $\mathrm{C}_{8}$-PEG.
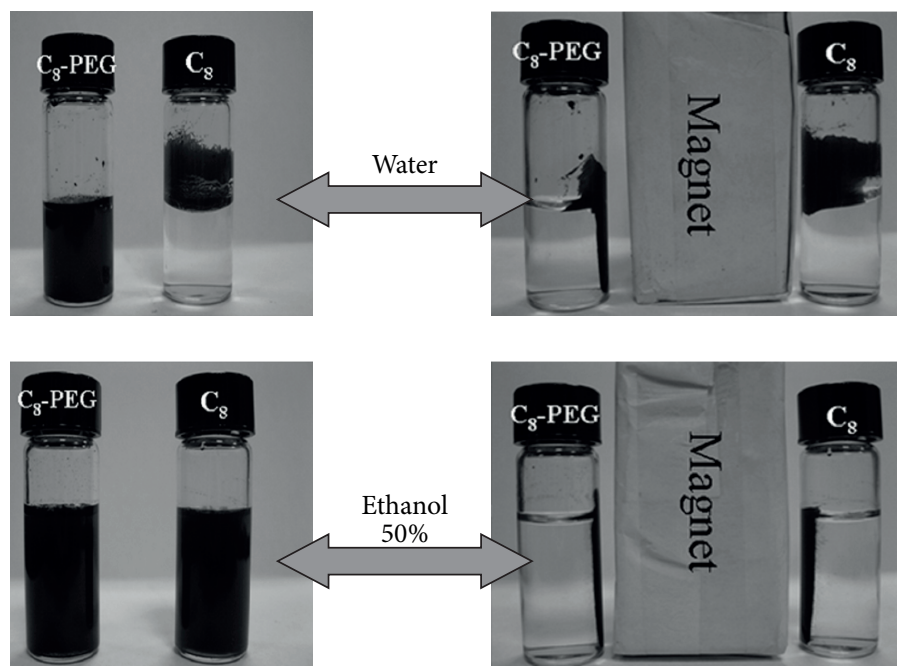

FIgURE 5: Comparison of $\mathrm{C}_{8}$ and $\mathrm{C}_{8}$-PEG dispersed in water.

modification of silica, the magnetic nanospheres showed core-shell structure, and the thickness of shell was estimated to be about 20-30 nm. No significant differences were observed between $\mathrm{C}_{8}$ and $\mathrm{C}_{8}$-PEG phase.

3.1.4. VSM. It is vitally important for MCT that the sorbents should possess sufficient magnetic and superparamagnetism property. VSM was employed to characterize magnetic properties of the obtained magnetic materials, and the VSM magnetization curves are shown in Figure 4. All magnetization curves were uniformly symmetric, confirming that the prepared products presented superparamagnetism. It can be seen that the saturation magnetization value of $\mathrm{Fe}_{3} \mathrm{O}_{4}, \mathrm{Fe}_{3} \mathrm{O}_{4} @ \mathrm{SiO}_{2}, \mathrm{C}_{8}$, and $\mathrm{C}_{8}$-PEG decreased, respectively, due to the increase of nonmagnetic density. However, the saturation magnetization value of $\mathrm{C}_{8}$-PEG was $50 \mathrm{emu} \mathrm{g}^{-1}$, which indicated that $\mathrm{C}_{8}$-PEG phase materials possessed superior magnetic property.
3.1.5. Dispersivity. The dispersivity was investigated in order to evaluate the difference of $\mathrm{C}_{8}$ and $\mathrm{C}_{8}-\mathrm{PEG}$. As shown in Figure 5, $20 \mathrm{mg}$ of magnetic materials was dispersed to $2 \mathrm{~mL}$ of water or $50 \%$ ethanol solution. From Figure 5(a), the left photograph displays that $\mathrm{C}_{8}$ and $\mathrm{C}_{8}$-PEG were dispersed to water by sonication, and the right photograph shows that the sorbents were collected by magnet after $10 \mathrm{~s}$. The dispersivity of $\mathrm{C}_{8}$-PEG in water was visibly better than $\mathrm{C}_{8}$. Figure $5(\mathrm{~b})$ illustrates that $\mathrm{C}_{8}$ and $\mathrm{C}_{8}$-PEG were dispersed to $50 \%$ ethanol solution, and no evident differences of dispersivity were observed. The results confirmed that the magnetic material can be separated easily from solution by an external magnet and $\mathrm{C}_{8}$-PEG phase presented superior property to $\mathrm{C}_{8}$.

3.2. Adsorption Tests. The adsorption capability of $\mathrm{C}_{8}$ and $\mathrm{C}_{8}$ PEG was researched by static tests with SMR as the target compound. As shown in Figure 6, the capacity of $\mathrm{C}_{8}$-PEG was about two times of $\mathrm{C}_{8}$ with the concentration of SMR 


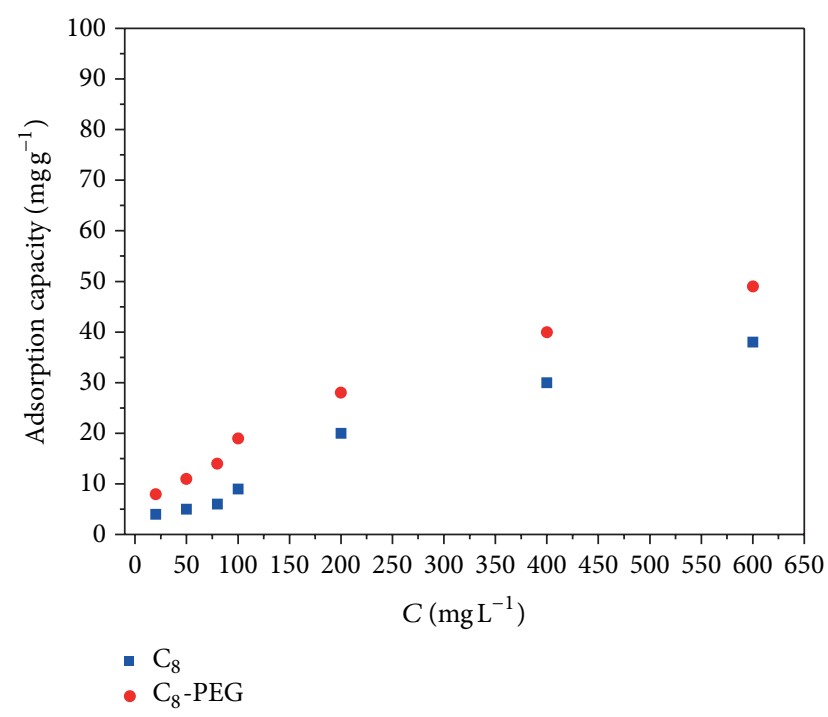

FIgURE 6: Static adsorption of SMR with $\mathrm{C}_{8}$ and $\mathrm{C}_{8}$-PEG.

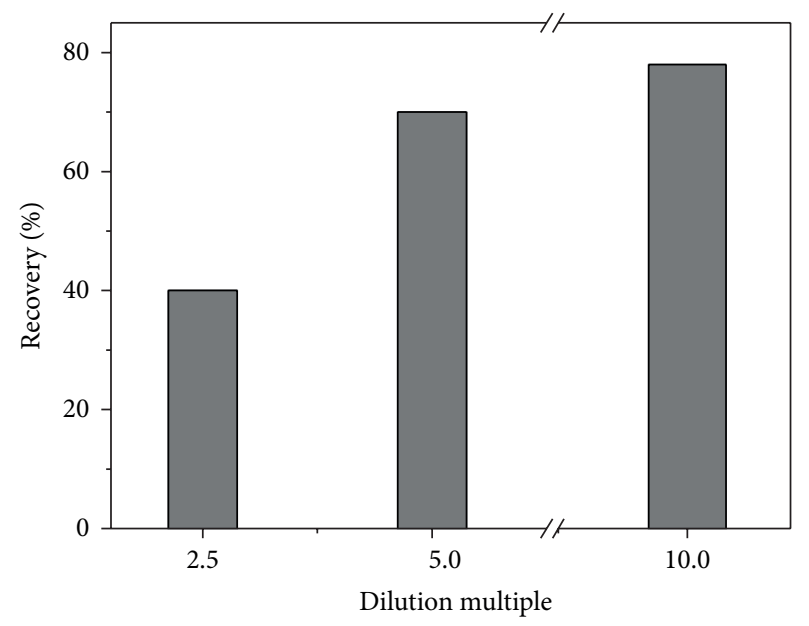

FIGURE 7: Recoveries of SMR from calf serum treated by $\mathrm{C}_{8}$-PEG.

in the range $20-100 \mathrm{mg} \mathrm{L}^{-1}$, and the differences decreased with the increase of SMR concentration. The differences were caused by their different dispersivity in sample solution. The sample solution used in static tests was obtained by diluting the methanol solution of SMR $1000 \mathrm{mg} \mathrm{L}^{-1}$. $\mathrm{C}_{8}$-PEG was better dispersed in sample solution than $\mathrm{C}_{8}$ when the SMR concentration was lower, and the differences of dispersivity between $\mathrm{C}_{8}$ and $\mathrm{C}_{8}$-PEG reduced while the concentration of SMR was higher. Furthermore, the hydrogen bond between $\mathrm{O}$ or $\mathrm{OH}$ of PEG and amine of SMR also contributed to the differences. The tests revealed that $\mathrm{C}_{8}$-PEG presented superior adsorption property to $\mathrm{C}_{8}$ for liquid samples.

3.3. Application in Real Samples. In order to study the feasibility of $\mathrm{C}_{8}$-PEG in the real application, it was applied to enrich SMR from calf serum and the spiked recoveries were investigated. As shown in Figure 7, the recoveries rose by $40 \%$ while the dilution ratio of the spiked samples (SMR,
$10 \mu \mathrm{g} \mathrm{mL}^{-1}$ ) increased from 2.5 to 10 . Under the condition of 10 -times dilution, $\mathrm{C}_{8}$-PEG could achieve better recovery without other pretreatments, confirming that it can reduce effectively the matrix effect, for example, the influences of protein, polypeptide, fat, and so on. The results demonstrated that $\mathrm{C}_{8}$-PEG owning biocompatibility can be applied in the pretreatment of biological samples.

\section{Conclusion}

The novel magnetic nano-spheres were prepared using $\mathrm{C}_{8}$ and polyethylene glycol as ligands. The prepared materials presented uniform sphere with size distribution about $200 \mathrm{~nm}$ and superparamagnetism. The results of tests proved that $\mathrm{C}_{8}$-PEG owned better dispersivity in aqueous samples, adsorption capability, and biocompatible property. $\mathrm{C}_{8}$-PEG was used to enrich SMR from calf serum and the spiked recoveries were $80 \%$. $\mathrm{C}_{8}$ - $\mathrm{PEG}$ performed superior potential in biological samples.

\section{Conflict of Interests}

The authors declare that there is no conflict of interests regarding the publication of this paper.

\section{Acknowledgments}

This work was supported by the Key Project of Henan Province Education Department Science and Technology Research (12A350002), the Doctoral Research Fund of Henan Chinese Medicine (BSJJ-2010-23), and the Open Project of Key Laboratory for Magnetism and Magnetic Materials of the Ministry of Education, Lanzhou University (LZUMMM 2010014).

\section{References}

[1] L. H. Reddy, J. L. Arias, J. Nicolas, and P. Couvreur, "Magnetic nanoparticles: design and characterization, toxicity and biocompatibility, pharmaceutical and biomedical applications," Chemical Reviews, vol. 112, no. 11, pp. 5818-5878, 2012.

[2] S. Y. Huang and Y. C. Chen, "Magnetic nanoparticle-based platform for characterization of histidine-rich proteins and peptides," Analytical Chemistry, vol. 85, no. 6, pp. 3347-3354, 2013.

[3] C. J. Tan, H. G. Chua, K. H. Ker, and Y. W. Tong, "Preparation of bovine serum albumin surface-imprinted submicrometer particles with magnetic susceptibility through core-shell miniemulsion polymerization," Analytical Chemistry, vol. 80, no. 3, pp. 683-692, 2008.

[4] W. Lu, Y. Shen, A. Xie, and W. Zhang, "Preparation and protein immobilization of magnetic dialdehyde starch nanoparticles," The Journal of Physical Chemistry B, vol. 117, no. 14, pp. 37203725, 2013.

[5] Z. Zou, M. Ibisate, Y. Zhou, R. Aebersold, Y. Xia, and H. Zhang, "Synthesis and evaluation of superparamagnetic silica particles for extraction of glycopeptides in the microtiter plate format," Analytical Chemistry, vol. 80, no. 4, pp. 1228-1234, 2008.

[6] Y. C. Li, Y. S. Lin, P. J. Tsai, C. T. Chen, W. Y. Chen, and Y. C. Chen, "Nitrilotriacetic acid-coated magnetic nanoparticles as 
affinity probes for enrichment of histidine-tagged proteins and phosphorylated peptides," Analytical Chemistry, vol. 79, no. 19, pp. 7519-7525, 2007.

[7] A. M. Nowicka, A. Kowalczyk, A. Jarzebinska et al., "Progress in targeting tumor cells by using drug-magnetic nanoparticles conjugate," Biomacromolecules, vol. 14, no. 3, pp. 828-833, 2013.

[8] E. Amstad, J. Kohlbrecher, E. Müller, T. Schweizer, M. Textor, and E. Reimhult, "Triggered release from liposomes through magnetic actuation of iron oxide nanoparticle containing membranes," Nano Letters, vol. 11, no. 4, pp. 1664-1670, 2011.

[9] L. Zhang, B. Liu, and S. Dong, "Bifunctional nanostructure of magnetic core luminescent shell and its application as solidstate electrochemiluminescence sensor material," Journal of Physical Chemistry B, vol. 111, no. 35, pp. 10448-10452, 2007.

[10] L. Qi, L. Wu, S. Zheng, Y. Wang, H. Fu, and D. Cui, "Cellpenetrating magnetic nanoparticles for highly efficient delivery and intracellular imaging of siRNA," Biomacromolecules, vol. 13, no. 9, pp. 2723-2730, 2012.

[11] P. Tiberto, G. Barrera, F. Celegato et al., "Magnetic properties of jet-printer inks containing dispersed magnetite nanoparticles," The European Physical Journal B, vol. 86, no. 4, pp. 1-6, 2013.

[12] Y. Song, S. Zhao, P. Tchounwou, and Y. M. Liu, "A nanoparticle-based solid-phase extraction method for liquid chromatography-electrospray ionization-tandem mass spectrometric analysis," Journal of Chromatography A, vol. 1166, no. 1-2, pp. 7984, 2007.

[13] X. Zhao, Y. Shi, Y. Cai, and S. Mou, "Cetyltrimethylammonium bromide-coated magnetic nanoparticles for the preconcentration of phenolic compounds from environmental water samples," Environmental Science and Technology, vol. 42, no. 4, pp. 1201-1206, 2008.

[14] X. Zhao, Y. Shi, T. Wang, Y. Cai, and G. Jiang, "Preparation of silica-magnetite nanoparticle mixed hemimicelle sorbents for extraction of several typical phenolic compounds from environmental water samples," Journal of Chromatography A, vol. 1188, no. 2, pp. 140-147, 2008.

[15] J. Li, X. Zhao, Y. Shi, Y. Cai, S. Mou, and G. Jiang, "Mixed hemimicelles solid-phase extraction based on cetyltrimethylammonium bromide-coated nano-magnets $\mathrm{Fe}_{3} \mathrm{O}_{4}$ for the determination of chlorophenols in environmental water samples coupled with liquid chromatography/spectrophotometry detection," Journal of Chromatography A, vol. 1180, no. 1-2, pp. 24-31, 2008.

[16] W. Yantasee, C. L. Warner, T. Sangvanich et al., "Removal of heavy metals from aqueous systems with thiol functionalized superparamagnetic nanoparticles," Environmental Science and Technology, vol. 41, no. 14, pp. 5114-5119, 2007.

[17] D. Qi, Y. Mao, J. Lu, C. Deng, and X. Zhang, "Phosphatefunctionalized magnetic microspheres for immobilization of $\mathrm{Zr}^{4+}$ ions for selective enrichment of the phosphopeptides," Journal of Chromatography A, vol. 1217, no. 16, pp. 2606-2617, 2010.

[18] Y. Liu, H. Li, and J. M. Lin, "Magnetic solid-phase extraction based on octadecyl functionalization of monodisperse magnetic ferrite microspheres for the determination of polycyclic aromatic hydrocarbons in aqueous samples coupled with gas chromatography-mass spectrometry," Talanta, vol. 77, no. 3, pp. 1037-1042, 2009.

[19] N. Yao, H. Chen, H. Lin, C. Deng, and X. Zhang, "Enrichment of peptides in serum by $\mathrm{C}_{8}$-functionalized magnetic nanoparticles for direct matrix-assisted laser desorption/ionization time-offlight mass spectrometry analysis," Journal of Chromatography A, vol. 1185, no. 1, pp. 93-101, 2008.

[20] Y. Zhang, R. Liu, Y. Hu, and G. Li, "Microwave heating in preparation of magnetic molecularly imprinted polymer beads for trace triazines analysis in complicated samples," Analytical Chemistry, vol. 81, no. 3, pp. 967-976, 2009.

[21] H. Niu, Y. Wang, X. Zhang, Z. Meng, and Y. Cai, “Easy synthesis of surface-tunable carbon-encapsulated magnetic nanoparticles: adsorbents for selective isolation and preconcentration of organic pollutants," ACS Applied Materials and Interfaces, vol. 4, no. 1, pp. 286-295, 2012.

[22] Y. Ji, J. Yin, Z. Xu et al., "Preparation of magnetic molecularly imprinted polymer for rapid determination of bisphenol A in environmental water and milk samples," Analytical and Bioanalytical Chemistry, vol. 395, no. 4, pp. 1125-1133, 2009.

[23] Y. Ji, X. Liu, M. Guan et al., "Preparation of functionalized magnetic nanoparticulate sorbents for rapid extraction of biphenolic pollutants from environmental samples," Journal of Separation Science, vol. 32, no. 12, pp. 2139-2145, 2009.

[24] Y. Hu, R. Liu, Y. Zhang, and G. Li, "Improvement of extraction capability of magnetic molecularly imprinted polymer beads in aqueous media via dual-phase solvent system," Talanta, vol. 79, no. 3, pp. 576-582, 2009.

[25] Q. Li, M. H. Lam, R. S. Wu, and B. Jiang, "Rapid magneticmediated solid-phase extraction and pre-concentration of selected endocrine disrupting chemicals in natural waters by poly(divinylbenzene-co-methacrylic acid) coated $\mathrm{Fe}_{3} \mathrm{O}_{4}$ coreshell magnetite microspheres for their liquid chromatographytandem mass spectrometry determination," Journal of Chromatography A, vol. 1217, no. 8, pp. 1219-1226, 2010.

[26] H. X. Zhang, M. C. Liu, and P. L. Zhu, "Preparation of a polyglycol- $\mathrm{C}_{8}$ bonded phase and its characteristics," Chromatographia, vol. 51, no. 7-8, pp. 437-442, 2000. 

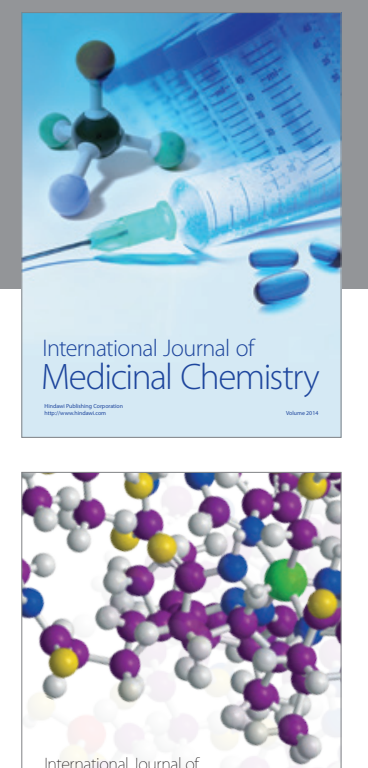

\section{Carbohydrate} Chemistry

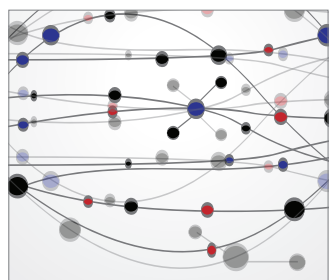

The Scientific World Journal
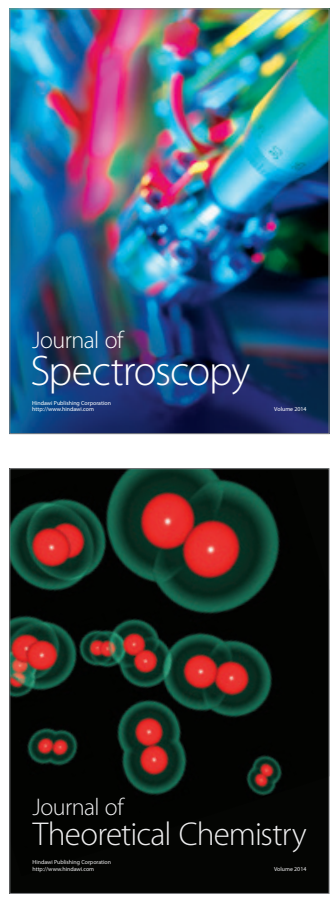
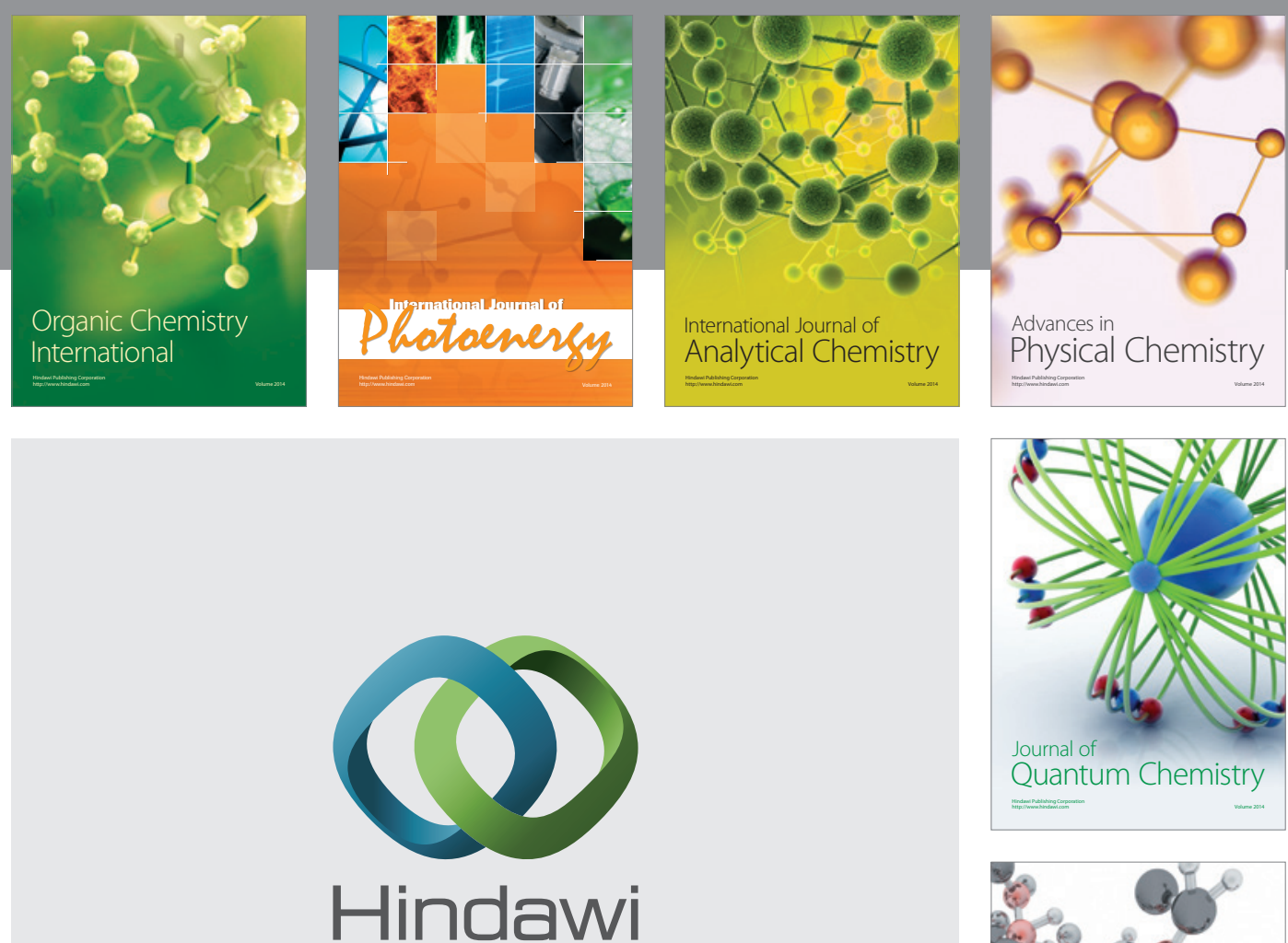

Submit your manuscripts at

http://www.hindawi.com

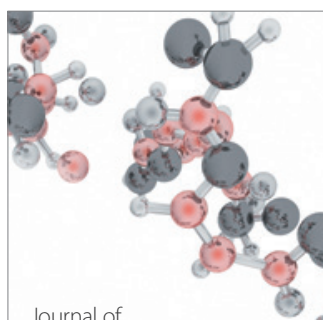

Analytical Methods

in Chemistry

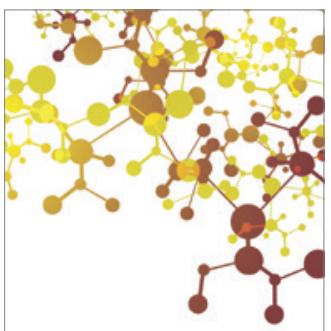

Journal of

Applied Chemistry

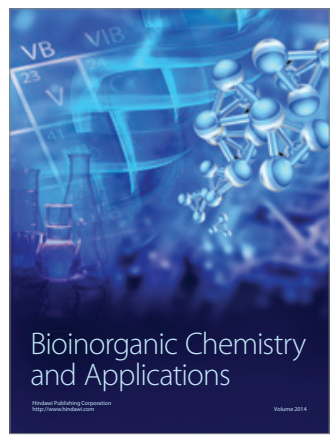

Inorganic Chemistry
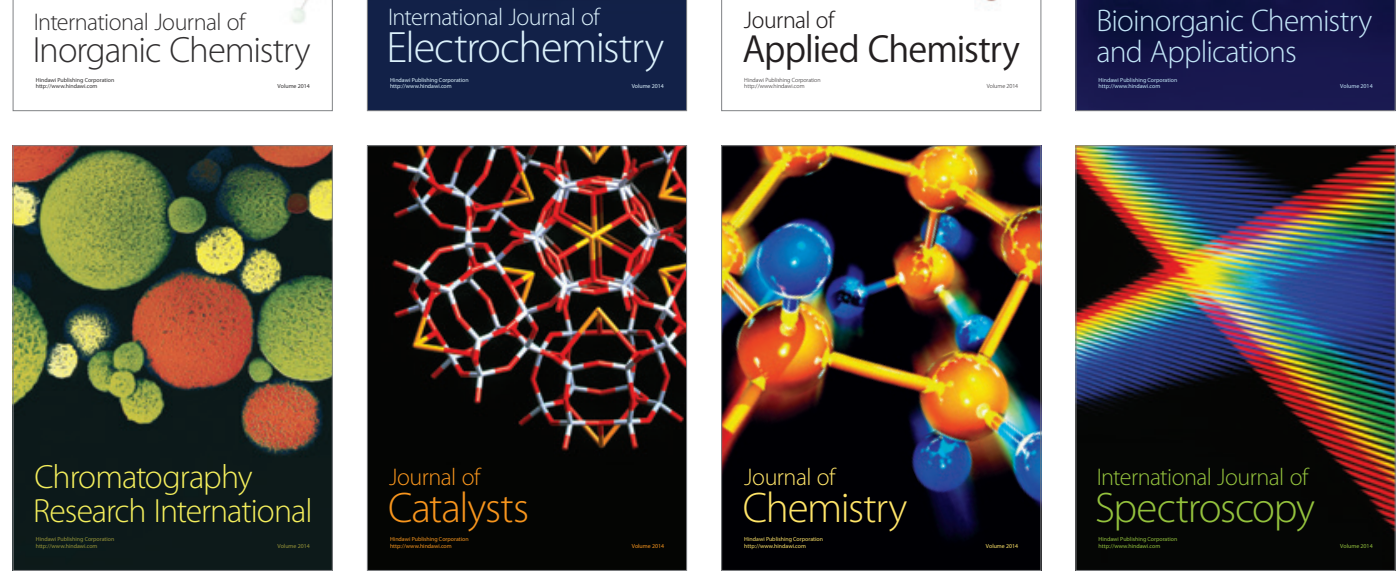